\title{
Disputes delay development of leprosy vaccine for India
}

\section{New Delhi}

Prolonged wrangling among Indian scientists is hampering efforts to produce a leprosy vaccine for the subcontinent. Four potential vaccines exist in varying states of development, but conflicting opinions, mutual distrust and competition between different groups of researchers is preventing the health ministry from deciding which to choose. The ministry has not yet given the go-ahead to what would be the world's largest trial of an armadilloderived vaccine developed under the Immunology of Leprosy programme of the World Health Organisation (WHO). The vaccine is already under trial in Venezuela and Malawi, and it had been hoped to conduct a larger trial at the Jalma Institute of Leprosy in Agra, run by the Indian Council of Medical Research (ICMR).

The trial is being opposed by the Bombay-based Cancer Research Institute (CRI), which claims to have developed an equally effective and cheaper vaccine, derived from cultivable mycobacteria.

Leishmaniasis
resurgent in India

\section{New Delhi}

LeISHMANIASIS, an insect-borne disease, has staged a comeback years after it was wiped out from India. In the past 12 months, some 22,000 cases and 160 deaths have been reported from the states of West Bengal, Bihar and Uttar Pradesh. There have also been cases in Tamil Nadu and Delhi.

Leishmaniasis is caused by a protozoan, leishmania, passed on to humans by sandflies. Sandflies are extremely sensitive to DDT, and had virtually been eradicated as a side-effect of malaria control in the 1950s. But after 1965, insecticide spraying was stopped under the government's modified anti-malaria strategy, resulting in a buildup of the sandfly population and a resurgence of the disease. In 1977, leishmaniasis killed 229 people in Bihar and since then has spread to adjoining states.

According to the Health Ministry, leishmaniasis is unlikely to become an epidemic if preventive measures are continued. A suggestion by an expert committee for a national control programme has been rejected. Instead, affected states have been asked to re-start door-to-door DDT spraying. India is producing sodium antimony gluconate, the conventional drug for treating victims, and is importing pentamidine isothionate for the 10 per cent of cases that do not respond to antimony treatment.

K.S. Jayaraman
Opponents of the WHO scheme say that India should be encouraged to develop an indigenous vaccine, rather than depend on an imported one. The CRI vaccine is in the third phase of clinical trial in a leprosyendemic district of Maharashtra. Some 10,000 people have been vaccinated, with a further 40,000 to be brought under the trial by 1991. CRI director Dr Mahadev G. Deo questions the need for an expensive trial of the WHO vaccine. Deo says that because the source of the CRI vaccine is a cultivable microorganism, it is simpler and cheaper to produce than the WHO vaccine, which relies on relatively expensive armadillos and an elaborate purification system. Critics of the WHO proposals are also adamant that a trial should not be started in India until the results of the Malawi and Venezuela studies are known.

The director of the Jalma institute, Dr H. Srinivasan, says that India will lose precious time by relying exclusively on the CRI vaccine. He contends that the WHO vaccine should be tried irrespective of the results from other countries, because of the variation in genetic make-up of the different populations

The issue is further complicated by a third potential vaccine, developed by Dr G. P. Talwar, at the National Institute of Immunology. Talwar's vaccine, also derived from a cultivable mycobacterium, has been approved for human trial, though not yet field-tested. It is currently being used on 200 patients in two Delhi hospitals to evaluate its therapeutic - but not prophylactic - value.

Dr M. D. Gupte, Jalma's deputy director and a member of the WHO steering committee, says that the WHO is prepared to study all three vaccines in a single, randomized trial. "If all of them are equally effective we will naturally opt for the Indian vaccine."

Talwar is agreeable, but Deo, who still has reservations about the cost and safety of the WHO vaccine (see Nature 328, 660; 1987 and 330, 690; 1987), has so far not consented.

Meanwhile, the Central Drug Research Institute in Lucknow has applied to the Drug Controller for a licence to test a fourth vaccine, also mycobacteriumderived.

The ICMR concedes that the situation is "confused" but has apparently made no moves itself to organize a trial using common protocol and design. In the meantime, Talwar and Deo are conducting their own tests, in the full knowledge that without an independent monitoring body the credibility of their results could be questioned.

K. S. Jayaraman

\section{OSHA standards}

Washington

The US Occupational Safety and Health Administration (OSHA) has set new standards for the exposure of workers to over 400 industrial chemicals. The acceptable level of exposure has been lowered for 234 substances, and standards have been established for the first time for another 168 chemicals. Contrary to the agency's usual practice of evaluating and regulating chemical substances one at a time, the exposure limits were adopted from an existing database maintained by an association of industrial hygienists. OSHA officials maintain that the new standards will reduce the number of deaths arising from exposure to dangerous chemicals in the workplace by up to 500 per year, but labour unions have opposed the across-the-board approach as too lenient.

The new standards will affect 3.7 million workers, and will cost the chemical industry an estimated $\$ 4,000$ million to implement. Carol Ezzell

\section{New head for LBL}

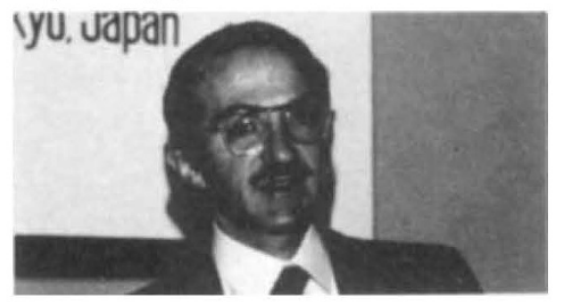

Berkeley

Charles Cantor is to leave Columbia University to head the Human Genome Center at Lawrence Berkeley Laboratory. Cantor developed the pulsed-field gel electrophoresis technique for separating very large fragments (up to 1,000 kilobases) of DNA, which promises to be vital to the genome mapping project. His expertise will be an important asset to the centre, which has elected to focus its genome-mapping efforts on the cloning and ordering of very large DNA fragments (see Nature 330, 9; 1987).

Marcia Barinaga

\section{Century of looking up}

\section{Berkeley}

THE University of California's Lick Observatory celebrated its one hundredth birthday on 1 June. The first observatory to be built on a mountain top, Lick sits at nearly 4,000 feet on Mt Hamilton, near San Jose. Its original 36-inch refractor telescope has made many historic discoveries. Lick has acquired six additional telescopes over the years, of which the largest and most powerful is the Shane 120-inch Reflector. Current projects include the Northern Proper Motion programme, which for more than $\mathbf{4 0}$ years has been recording shifts in Milky Way stars, in an effort to understand the Galaxy's rotation.

Marcia Barinaga 